\title{
The effect of disclosure on adherence to antiretroviral therapy among adults living with HIV in Ethiopia: a systematic review and meta-analysis
}

Getenet Dessie ${ }^{1 *}$, Fasil Wagnew ${ }^{2}$, Henok Mulugeta $^{2}$, Dessalegn Amare ${ }^{1}$, Dube Jara ${ }^{3}$, Cheru Tesema Leshargie ${ }^{4}$, Ayenew Negesse ${ }^{5}$, Swati Rayasam ${ }^{6}$ and Sahai Burrowes ${ }^{7}$

\begin{abstract}
Background: Several factors have been identified as being associated with increased adherence to antiretroviral therapy, including sero-status disclosure; however, studies examining the effect of disclosure on ART adherence in Ethiopia have had inconsistent findings. This systematic review and meta-analysis therefore aims to estimate the pooled effect of disclosure on adherence to ART among adults living with HIV in Ethiopia.
\end{abstract}

Methods: We performed a systematic search for articles reporting on peer-reviewed, quantitative, English-language observational studies of reporting the association between self sero-status disclosure and good ART adherence in adults living with HIV/AIDS in Ethiopia during published from 2010 to 2015. We searched four electronic databases: PubMed/Medline, the World Health Organization's Hinari portal (which includes the SCOPUS, African Index Medicus, and African Journals Online databases) for studies from December 1, 2017 to January 30, 2018. We also searched university repositories and conference abstracts for unpublished studies. We conducted a meta-analysis for the pooled effect of adherence using a random effects model in Stata version 14 and assessed publication bias using the Egger's test for funnel plot asymmetry.

Results: Our search returned in 179 studies, of which seven (3.9\%), were eligible and included in the final meta-analysis. The seven included studies were conducted from 2010 to 2015. Our analysis found that disclosure had a significant effect on the adherence to ART in adult patients living with HIV. Patients who disclosed were 1.64 times more likely to have good adherence to ART compared with those who did not (OR: 1.64, 95\% Cl: 1.11, 2.42). The small number of studies eligible for review and differences in study definitions of adherence and disclosure were the main limitations of this study.

Conclusion: This review found a statistically significant positive effect of disclosure status on the adherence to ART in adult patients living with HIV in Ethiopia. This suggests that Ethiopia's national treatment and prevention programs should redouble efforts to encourage self-disclosure among people living with HIV/AIDS. Encouraging supportive social environments for disclosure, and promoting partner notification and partner disclosure support initiatives might be particularly helpful in this regard.

Keywords: Adherence, Antiretroviral therapy, HIV/AIDS, Disclosure, Ethiopia

\footnotetext{
* Correspondence: ayalew.d16@gmail.com

${ }^{1}$ Department of Nursing, school of health science, College of medicine and

Health Science Bahr Dar University, P.O. Box 79, Bahir Dar, Ethiopia

Full list of author information is available at the end of the article
}

(c) The Author(s). 2019 Open Access This article is distributed under the terms of the Creative Commons Attribution 4.0 International License (http://creativecommons.org/licenses/by/4.0/), which permits unrestricted use, distribution, and reproduction in any medium, provided you give appropriate credit to the original author(s) and the source, provide a link to the Creative Commons license, and indicate if changes were made. The Creative Commons Public Domain Dedication waiver (http://creativecommons.org/publicdomain/zero/1.0/) applies to the data made available in this article, unless otherwise stated. 


\section{Background}

The unprecedented global response to the HIV/AIDS pandemic of the 1990s brought millions of people living with HIV/AIDS (PLWHA) access to lifesaving antiretroviral therapy (ART). The success of these programs and the continuing challenges in developing and implementing effective HIV prevention interventions have meant that the number of people receiving ART has continued to grow steadily. It is estimated that 21.7 million people worldwide were receiving ART by the end of 2017 [1]. In the region of the world most heavily affected by HIV/AIDS-eastern and southern Africa-UNAIDS estimates that 65\% of PLWHA are receiving ART [2]; in Ethiopia, 75\% of adult PLWHA (approximately 415,578 people) were receiving ART in 2017 [2]. While the growth of ART treatment programs in subSaharan Africa is impressive, these programs are fragile: heavily reliant on a few, low-cost ART drug regimens primarily financed by external donors [3]. High levels of patient adherence to ART (e.g., 95\% of doses taken), crucial for maintaining the health of PLWHA, have become even more important in this context of limited antiretroviral drug choice, as adherence is crucial for preventing resistance to these drugs. Unfortunately, maintaining good patient adherence to ART in these programs continues to be challenging.

Studies in low-income countries have identified several factors that affect adherence to ART, of which disclosure of patient sero-status is a major contributing factor [4-7]. Social support, access to mental health care, counseling, educational interventions, and good nutrition have also been found to be associated with increased adherence to ART [4-7]. Treatment factors such as the complexity of the drug regimen and provider factors such as the quality of relationships between providers and patients have also been found to influence adherence rates [8-10].

The disclosure of one's HIV status to relatives, friends, and sexual partners has significant health implications. Studies have found that patients who disclosed their serostatus had better social support; stronger family and relationship cohesion; reductions in anxiety and depression; improvements in physical health, emotional support, and financial support; and were better able to take ART freely and to improve their ART adherence [11-13]. Conversely, high levels of employment discrimination, fear of being abandoned by family members, fear of divorce, and communication difficulties were the most important barriers to disclosing sero-status $[11,14-16]$.

While the relationship between disclosure and adherence is fairly well-established in high-income settings, fewer studies have investigated the association in sub-Saharan Africa. Studies that have examined the association between ART adherence and disclosure among PLWHA in Ethiopia in particular have presented inconsistent results, with some finding strong positive associations and others finding limited or even negative associations between the two factors
$[17,18]$. The one existing systematic review of factors related to adherence in sub-Saharan Africa included only a handful of articles that examined the effect of disclosure specifically [6].

This systematic review and meta-analysis seeks to fill the gaps in the Ethiopian literature by estimating the pooled effect of disclosure status on adherence to ART among adult patients living with HIV in Ethiopia. Understanding Ethiopia's specific adherence challenges is important, as the country has a large national ART treatment program serving extremely heterogeneous geographic regions and socio-economic groups. Although the country's overall adult HIV prevalence has declined significantly in the last two decades [19], the epidemic is spread among the adult population with large geographic and sub-population variation in prevalence and important regional hotspots with very high prevalence occurring in large urban areas and certain regions such as Gambella [20]. Determining whether the impact of disclosure on adherence is as strong in Ethiopia as in other settings, or whether is there are regional or subpopulation variation in the importance of disclosure might, therefore, be useful for policy makers trying to determine the amount of resources to dedicate to disclosure promotion activities. Being efficient in HIV program resource allocation is particularly important as Ethiopia continues to expand its national program to rural areas while shifting donor priorities and institutional changes $[3,21]$. We hope that our findings will be useful to these stakeholders who are interested in designing appropriate interventions to improve ART adherence and sero-status disclosure among PLWHA.

\section{Methods}

We conducted this systematic review and meta-analysis per PRISMA guidelines [22]. This study was not pre-registered.

\section{Eligibility criteria, data sources and search strategy}

We performed our electronic database search using PubMed/MEDLINE, Hinari (a World Health Organization sponsored database that provides low-income researchers access to the SCOPUS, African Index Medicus, and African Journals Online databases), Google Scholar, and the Cochrane Library.

We built a search strategy by using the Boolean operator "and/or" with combinations of keywords. For example, ("adherence" AND "antiretroviral" AND "association" OR "determinant" AND "disclosure" AND "therapy" AND "Ethiopia"). For PubMed's advance search, we used Medical Subject Headings (MeSH terms, See Appendix) to expand the search strategy. Unpublished studies were also accessed through the Addis Ababa University library. The reference lists of included studies were also reviewed to retrieve additional studies. The Cochrane library was explored in an 
effort to confirm whether there were existing systematic reviews or meta-analyses and to check the availability of ongoing projects related to the current systematic review and meta-analysis.

Eligible publications were peer reviewed, Englishlanguage scholarly articles or $\mathrm{PhD}$ dissertations, and peer reviewed conference abstracts published between the years 2010 to 2015; for observational, quantitative studies that took place in Ethiopia; and that investigated the association between sero-status disclosure and adherence to ART among adults (age 18 years and greater) living with HIV and currently receiving antiretroviral therapy. We excluded the studies focusing on children, review articles, and articles that had methodological problems after being reviewed by two authors using the Newcastle-Ottawa Scale (NOS) criteria [23].

\section{Data abstraction and quality assessment}

Two reviewers screened the abstracts and titles of articles found by the search for relevance and for match with our inclusion criteria. When it was unclear whether an abstract was relevant or not, it was included for retrieval. The two reviewers then retrieved the full text of the screened articles then assessed them for relevance based on their topic, study outcomes, and methodology. Articles deemed irrelevant to the study were removed at this stage and the full text of the remaining articles reviewed for quality, by two study investigators using the Newcastle-Ottawa Scale (NOS). Articles whose NOS quality scores were less than an average score of six by the two investigators were excluded from the final analysis. Discrepancies were resolved with a third reviewer whenever appropriate.

\section{Data analysis and synthesis}

Data were extracted from each of the original studies using Microsoft Excel and Stata version 14 for further analysis. Heterogeneity was checked by using an $\mathrm{I}^{2}$ test statistic [24]. We used a forest plot to visualize the presence of heterogeneity. Since there was relatively moderate heterogeneity, we used a random effects model for analysis to estimate the pooled effect. We also used funnel plot asymmetry and Egger's test of the intercept to check for publication bias. [25]. To verify the results, two researchers independently computed the main statistical analyses and checked for consistency. The effect size estimates were converted to odds ratios, as all included studies compared two groups and reported dichotomous outcomes.

\section{Results}

Selection and identification of original studies

Our search identified 179 published articles, of which 148 articles were found in the PubMed, Hinari and Scholar databases; the remaining were found in university libraries, conference abstracts, or reference lists (see Fig. 1). Of the total identified, 154 articles were excluded at initial assessment after reviewing their titles based on the inclusion criteria. The abstracts and full text of the remaining 25 studies were assessed and screened for eligibility criteria and whether they reported the outcome variable of interest (adherence); 18 articles were excluded due to failure to meet inclusion criteria. Two articles were excluded due to poor quality based on the selection criteria $[17,26]$. Four articles were excluded because their regression tables did not include disclosure as an independent variable [27-30]. Two articles were excluded because their results did not report odds ratios or statistics that could be converted into odds ratios [31, 32]. Seven studies met the eligibility and quality criteria and were included in the analysis.

\section{Study measures}

For the purpose of this review, we allowed the broadest definition of "disclosure" employed by the studies under review, defining it as disclosure to community members (inclusive of family, religious leaders, friends etc.). We also the broadest definition of "good adherence" employed by the studies under review: defining it as fewer than three missed doses per day over the study period. Table 1 below lists how each of the seven included studies defined disclosure and good adherence. Our principal summary measure was odds of "good adherence", i.e., an odds ratio either directly reported or calculated from the study outcomes presented.

\section{Characteristics of included studies}

The seven studies included in the review were all crosssectional [18, 33-38]. They had a total of sample of 2260 adults living with HIV/AIDs in Ethiopia and were conducted from 2010 to 2015 in various regions of the country. The study sample sizes ranged from 233 to 422 participants $[36,38]$. Of the seven studies included in the final analysis, three were conducted in the Amhara region $[18,34,36]$ and two were conducted in the Southern Nations Nationalities and People (SNNPR) region $[33,35]$. The remaining two studies were conducted in Oromia [38] and Harari regions [37] respectively.

The highest odds ratio (OR) for impact of sero-status disclosure on adherence was 3.41, reported for a study conducted in Oromia region [38]. The smallest odds ratio for sero-status disclosure (0.84) was reported in study conducted in Amhara region [34]. The latter study was the only study included which reported an OR below 1 (or a negative impact of disclosure on adherence). Although it went unmentioned by the study authors, lack of social support and its negative impact on both adherence and disclosure is well understood in the literature [39].

All included studies were conducted within a hospital or clinic environment. Geographically, they spanned 


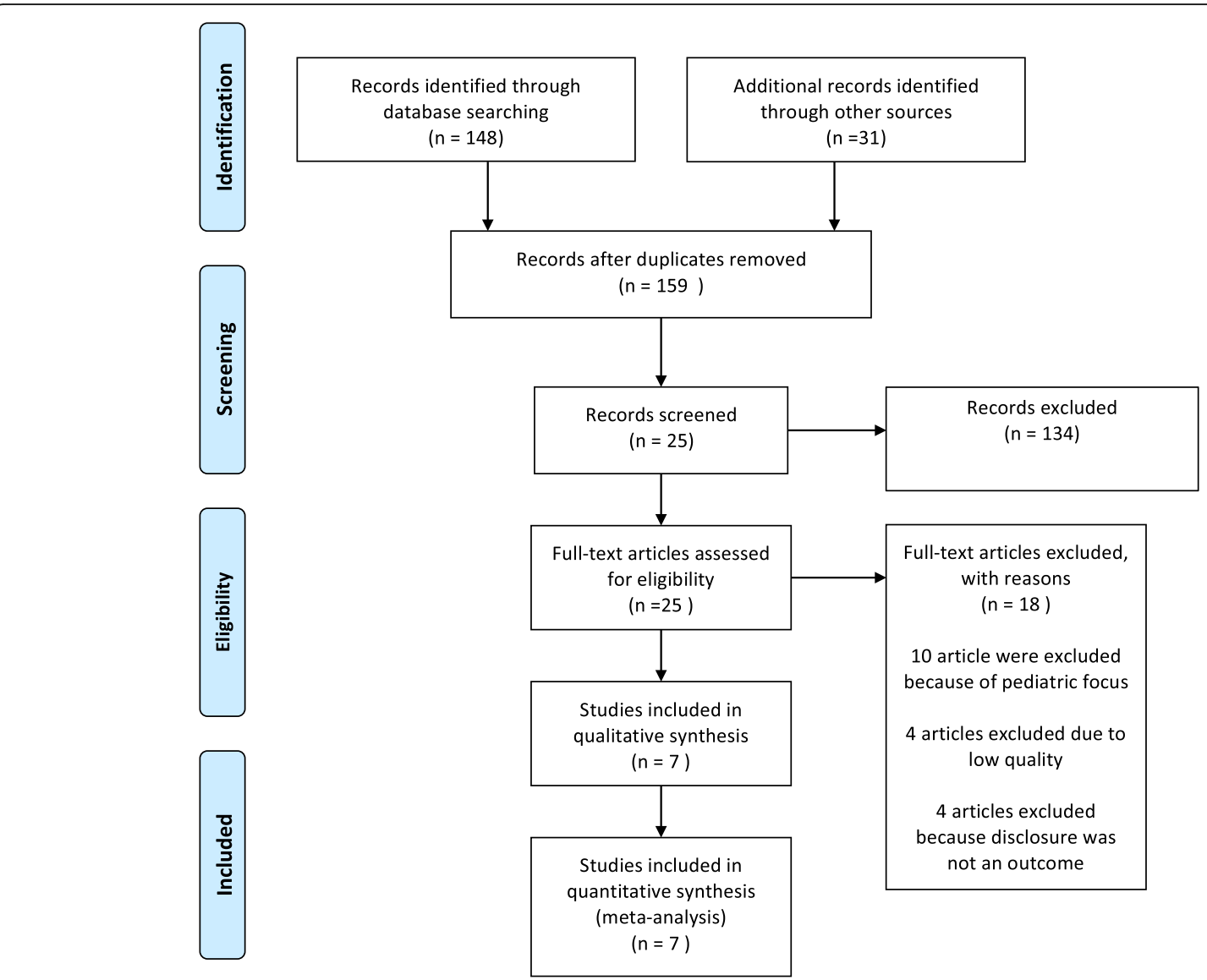

Fig. 1 PRISMA Flow diagram showing the procedure of selecting studies for meta-analysis, 2010-2015, Ethiopia

Table 1 Characteristics of included studies for meta-analysis, 2010-2015, Ethiopia

\begin{tabular}{|c|c|c|c|c|c|c|c|c|c|}
\hline \multirow{2}{*}{ Study } & \multirow[t]{2}{*}{ Author } & \multirow{2}{*}{$\begin{array}{l}\text { Publication } \\
\text { year }\end{array}$} & \multirow[t]{2}{*}{ Region } & \multirow{2}{*}{$\begin{array}{l}\text { Sample } \\
\text { size }\end{array}$} & \multirow[t]{2}{*}{ Good Adherence Definition } & \multirow[t]{2}{*}{ Disclosure Outcomes } & \multicolumn{2}{|c|}{ Good adherence } & \multirow[t]{2}{*}{ OR } \\
\hline & & & & & & & $\begin{array}{l}\text { Among } \\
\text { disclose }\end{array}$ & $\begin{array}{l}\text { Among } \\
\text { non- } \\
\text { disclose }\end{array}$ & \\
\hline 1 & $\begin{array}{l}\text { Mitiku et al. } \\
\text { [37] }\end{array}$ & 2013 & Harari & 239 & $\begin{array}{l}>95 \% \text { of prescribed ARV drugs for the } \\
\text { past } 7 \text { days. }\end{array}$ & Family or others & $164 / 208$ & $44 / 208$ & 1.09 \\
\hline 2 & $\begin{array}{l}\text { Mohammed } \\
\text { et al. [38] }\end{array}$ & 2015 & Oromia & 237 & $\begin{array}{l}<3 \text { missed doses/day over study } \\
\text { period }\end{array}$ & Community & $175 / 197$ & 22/197 & 3.41 \\
\hline 3 & $\begin{array}{l}\text { Ketema et al. } \\
\text { [36] }\end{array}$ & 2015 & Amhara & 422 & $\begin{array}{l}0 \text { missed dose during the } 30 \text {-day } \\
\text { period prior to filling out the self- } \\
\text { report. }\end{array}$ & $\begin{array}{l}\text { Religious leaders and } \\
\text { others }\end{array}$ & $357 / 422$ & $65 / 422$ & 1.96 \\
\hline 4 & $\begin{array}{l}\text { Alagaw et al. } \\
{[33]}\end{array}$ & 2013 & SNNPR & 357 & $\begin{array}{l}>=95 \% \text { of prescribed drugs in } \\
\text { past } 7 \text { days. }\end{array}$ & $\begin{array}{l}\text { No specifics regarding } \\
\text { disclosure }\end{array}$ & $281 / 312$ & $31 / 312$ & 2.59 \\
\hline 5 & $\begin{array}{l}\text { Tsega et al. } \\
{[18]}\end{array}$ & 2015 & Amhara & 351 & $\begin{array}{l}<3 \text { missed doses over the entire time } \\
\text { of therapy (Range: }>6 \text { mo to }<3 \mathrm{yr} \text { ) }\end{array}$ & Family & $265 / 284$ & $19 / 284$ & 1.13 \\
\hline 6 & Gelan [35] & 2010 & SNNPR & 277 & $\begin{array}{l}\text { Patients who reported an intake of } \\
95 \% \text { or more of the prescribed } \\
\text { medication }\end{array}$ & $\begin{array}{l}\text { Partner, family, relatives, } \\
\text { friends and community }\end{array}$ & $86 / 182$ & $96 / 182$ & 1.85 \\
\hline 7 & $\begin{array}{l}\text { Asmare et al. } \\
\text { [34] }\end{array}$ & 2014 & Amhara & 377 & $<3$ missed doses per month & Family/Relatives & $37 / 55$ & $18 / 55$ & 0.85 \\
\hline
\end{tabular}


three of the most populous regions in Ethiopia and contained a mix of both rural and urban populations.

\section{The effect of disclosure on adult antiretroviral therapy adherence}

We found significant heterogeneity across studies $\left(\mathrm{I}^{2}=\right.$ $42.9 \%, p=0.105$ ), which means that using a fixed effects model would have led to an unreliable estimate. Therefore, we used a random effects model to estimate the pooled effect of disclosure on the adherence reported by the seven studies with inverse variance. We found no evidence of publication bias after using a funnel plot of asymmetry and Egger's test. Although visual examination of the funnel plot shows it to be asymmetric, Egger's test of the intercept (B0) was 0.47 (95\% CI: $-5.16,6.11 \mathrm{p}=0$. 0.28) (see Fig. 2).

Our meta-analysis found that sero-status disclosure had statistically significant effects on adherence to ART. Adults living with HIV who disclosed their sero-status were 1.64 times more likely to have good adherence compared to patients who did not disclose (OR: 1.64, 95\% CI: 1.11, 2.42).

\section{Discussion}

This systemic review and meta-analysis attempted to estimate the pooled effect of disclosure on adherence to ART among adults living with HIV in Ethiopia. Our analysis indicated that disclosure of sero-status had a statistically significant effect on adherence to ART. The odds of having good adherence among adults living with HIV who disclosed their sero-status were $64 \%$ higher than those who did not disclose their sero-status with $(\mathrm{OR}=1.64(95 \% \mathrm{CI}$ :
1.11, 2.42)). The positive relationship between HIV disclosure status and adherence to ART in our analysis is consistent with the findings of primary studies and reviews conducted in high income settings, that found that HIV status disclosure was strongly correlated with ART drug adherence [40-42]. Our results are also in line with those from a systematic review of factors associated with adherence in sub-Saharan Africa, which found that disclosure among people living with HIV had a positive effect on ART adherence (OR $=3.46 ; 95 \% \mathrm{CI} 2.04$ to 5.89) [6].

Our estimated pooled odds ratios are more modest than the odds reported in the sub-Saharan Africa systematic review, reflecting perhaps the small number of studies that we had under review and the heterogeneity in the definitions of the independent and dependent variables. Another possible explanation may be that the positive impact of disclosure in Ethiopia is dampened (or reversed in the case of the study which found that it has negative impact) by a lack of social support in the country. Self-disclosure by itself does not improve adherence. Rather, one of the reasons that self-disclosure is important is that it helps PLWHA to ask for and receive crucial social support and, and, this in turn promotes better mental health and good ART adherence [39, 43]. In contrast, depression and poor social support have been show to negatively affect ART drug adherence $[6,44]$. The relationship between social support and disclosure may be bi-directional in that poor social support may preclude disclosure if PLWHA do not feel safe in sharing their status. The literature and the studies included in our review suggest that the relationships between poor adherence and disclosure might be explained, in part, by inadequate social support leading to

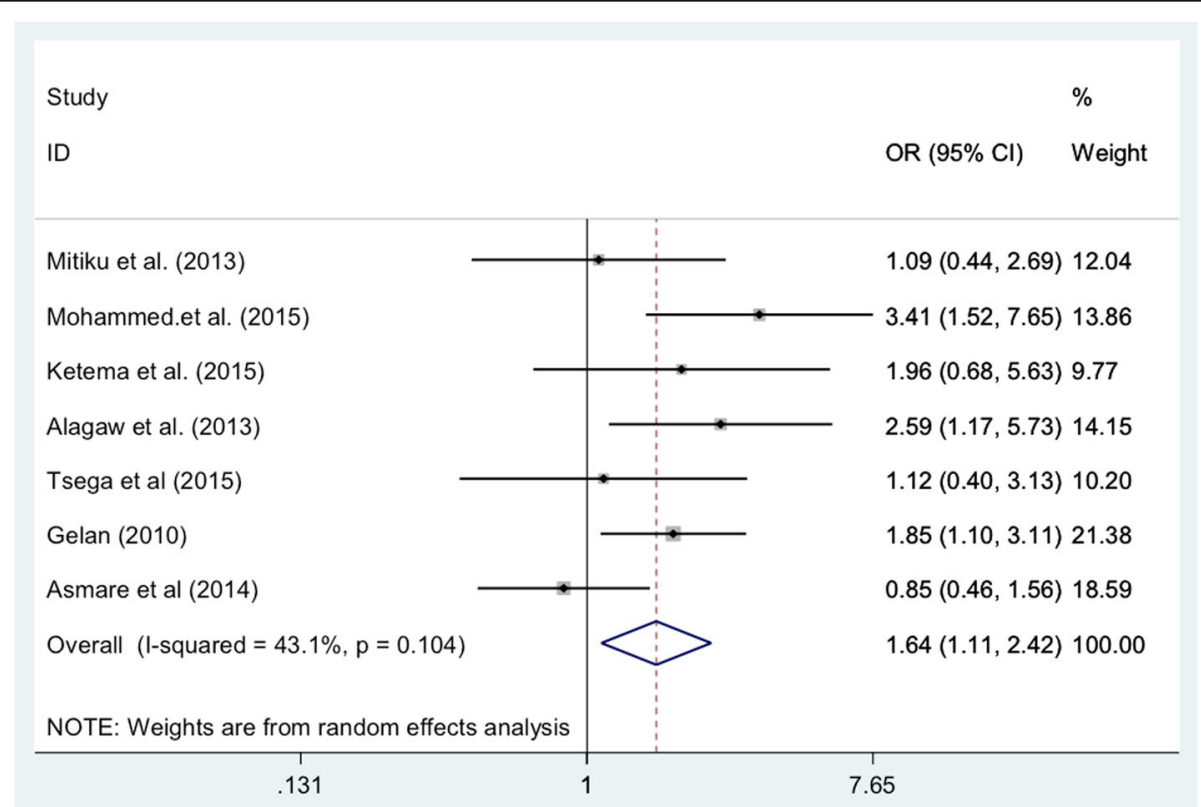

Fig. 2 Forest plot of studies on the effect of disclosure on ART adherence among adult HIV patients, 2010-2015, Ethiopia 
fear of taking drugs in front of family members; this is then leads patients to hide their sero-status from relatives, making it difficult to take medication at a prescribed time [45]. This suggests that programs to create supportive environments in which people feel safe to disclose, might have more of an impact on adherence than promoting disclosure on its own. Promoting support from key, highly respected parties such religious leaders, and providing counseling support for disclosure between couples and with relatives (rather than promoting disclosure to anyone) may be particularly important.

Our review adds to the literature by aggregating and highlighting articles germane to Ethiopian experiences. Ethiopia's HIV epidemic is different than other epidemics in the region in that it is widely spread across the country, it is highly concentrated in certain geographic regions and in specific vulnerable populations. The country also has unique religious and socio-political structures in the Ethiopian Orthodox Church and the Gada System of the Oromo for example, which have the potential to influence the level of social support for PLWHA and their ability to disclose their HIV status. In addition, care-seeking behavior in Ethiopia is idiosyncratic, with its own traditions of alternative medicines and treatments such as the extensive use of holy water, among other things [36, 38, 46]. The use of these alternative treatments may also influence adherence and disclosure.

While many HIV prevention strategies are transferrable across settings, it is critical to have country-specific culturally relevant solutions for HIV prevention and treatment. Country-specific studies such as ours, aid in the development of these solutions. Our findings coupled with that from the literature, underscore the importance of active self-disclosure of sero-status and may serve as an important reminder for policy makers and program planners to strengthen existing strategies and explore novel or more aggressive strategies such as partner notification to support PLWHA to take this difficult step.

\section{Limitations}

There are several limitations to this study. First our search yielded only a modest number of articles to review. Second, our findings were the pooled effect of many crosssectional study designs, which are limited in their ability to draw upon causal inferences. The small number of studies included in the review and the patchiness of the data on respondent characteristics that they reported also limited our ability to conduct sub-group analyses of the studies in order to better explain the heterogeneity of the studies. Another important limitation is that the articles reviewed came primarily from smaller journals where the extent of peer review was difficult to assess, or from nonpeer reviewed dissertations. In addition, although we followed standard PRISMA protocols, we must note that our study was not pre-registered. Finally, and most important, the studies that we reviewed lacked of standardized definitions for both good adherence and disclosure which may have increased the heterogeneity of our findings.

\section{Conclusion}

Our systematic review and meta-analysis demonstrated that disclosure of HIV sero-status had a statistically significant positive effect on adherence to ART among adults living with HIV in Ethiopia. This suggests that Ethiopia's national treatment and prevention programs should redouble efforts to encourage self-disclosure among people living with HIV/AIDS. Partner notification and partner disclosure support initiatives might be particularly helpful in this regard. Counseling guidelines for health professionals who work in HIV treatment and testing should emphasize discussing disclosure with patients. Future research should focus on documenting the ART support needs of priority vulnerable adult populations in Ethiopia especially sex workers, seasonal laborers, women, and men who have sex with men and determining the factors hinders them from disclosing and adhering to ART in order to identify solutions for managing their care compassionately and effectively.

\section{Appendix}

\section{PubMed Advanced Search Terms}

(((((adherence[All Fields] AND ("anti-retroviral agent$\mathrm{s}$ "[Pharmacological Action] OR "anti-retroviral agents"[$\mathrm{MeSH}$ Terms] OR ("anti-retroviral"[All Fields] AND "agents"[All Fields]) OR "anti-retroviral agents"[All Fields] OR "antiretroviral"[All Fields])) AND ("association" [MeSH Terms] OR "association"[All Fields])) OR ("association"[MeSH Terms] OR "association"[All Fields])) AND ("disclosure"[MeSH Terms] OR "disclosure"[All Fields])) AND ("therapy"[Subheading] OR "therapy"[All Fields] OR "therapeutics"[MeSH Terms] OR "therapeutics"[All Fields])) AND ("ethiopia"[MeSH Terms] OR "ethiopia"[All Fields])

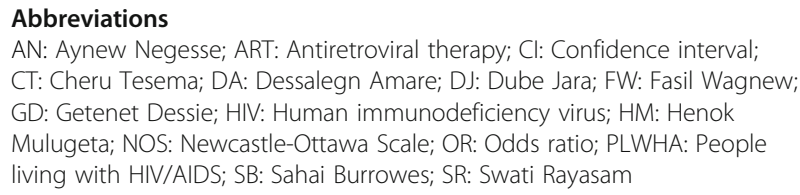

\section{Acknowledgments}

We would like to thank all authors of studies included in this systematic review and meta-analysis.

\section{Authors' contributions}

GD developed the protocol and involved in the design, selection of study, data extraction, statistical analysis and developing the initial drafts of the manuscript. GD, FW, HM, AN, CT, DJ, DA, SB and SR involved in data extraction, quality assessment, statistical analysis. FW, DA, GD, HM SB and SR prepared and revising subsequent drafts. DJ, DA, GD, SB, and SR prepared and edited the final draft of the manuscript. All authors read and approved the final draft of the manuscript. 


\section{Funding}

No funding was obtained for this study.

\section{Availability of data and materials}

All data are available in the document.

\section{Ethics approval and consent to participate}

Not applicable.

\section{Consent for publication}

Not applicable.

\section{Competing interests}

The authors declared that they have no competing interests.

\section{Author details}

'Department of Nursing, school of health science, College of medicine and Health Science Bahr Dar University, P.O. Box 79, Bahir Dar, Ethiopia.

${ }^{2}$ Department of Nursing, College of Health Science Debre Markos University, P.O. Box 269, Debre Markos, Ethiopia. ${ }^{3}$ Department of Public Health, College of Health Science Debre Markos University, P.O. Box 269, Debre Markos, Ethiopia. ${ }^{4}$ Department of Environmental Health, College of Health Science Debre Markos University, P.O. Box 269, Debre Markos, Ethiopia. ${ }^{5}$ Department of Human Nutrition and Food Sciences, College of Health Science Debre Markos University, P.O. Box 269, Debre Markos, Ethiopia. ${ }^{6}$ Independent Researcher, Berkeley, CA, USA. ${ }^{.}$Public Health Program, College of Education and Health Sciences, Touro University California, Vallejo, USA.

Received: 9 March 2018 Accepted: 31 May 2019

Published online: 17 June 2019

\section{References}

1. UNAIDS: ending the AIDS epidemic for adolescents, with adolescents. A practical guide to meaningfully engage adolescents in the AIDS response,2016.

2. UNAIDS: Joint United Nations Programme on HIV/AIDS. In.; 2017.Available at http://www.unaids.org/en/regionscountries/countries/ethiopia.

3. Brief HP: Ethiopia's emerging HIV financing gap: the need for increased domestic funding. November, 2018.Available at http://www. healthpolicyplus.com/ns/pubs/10265-10479-HIVFinancingEthiopia.pdf.

4. Li L, Lee SJ, Wen Y, Lin C, Wan D, Jiraphongsa C. Antiretroviral therapy adherence among patients living with HIV/AIDS in Thailand. Nurs Health Sci. 2010;12(2):212-20.

5. Atuyambe LM, Sseguija E, Ssali S, Tumwine C, Nekesa N, Nannungi A, Ryan G, Wagner G. HIV/AIDS status disclosure increases support, behavioural change and, HIV prevention in the long term: a case for an Urban Clinic, Kampala, Uganda. BMC Health Serv Res. 2014;14(1):276.

6. Heestermans T, Browne JL, Aitken SC, Vervoort SC, Klipstein-Grobusch K. Determinants of adherence to antiretroviral therapy among HIV-positive adults in sub-Saharan Africa: a systematic review. BMJ global health. 2016; 1(4):e000125.

7. Azia IN, Mukumbang FC, Van Wyk B. Barriers to adherence to antiretroviral treatment in a regional hospital in Vredenburg, Western cape, South Africa. Southern African J HIV Med. 2016;17(1):1-8.

8. Gifford AL, Bormann JE, Shively MJ, Wright BC, Richman DD, Bozzette SA Predictors of self-reported adherence and plasma HIV concentrations in patients on multidrug antiretroviral regimens. J Acquir Immune Defic Syndr. 2000;23(5):386-95.

9. Flickinger TE, Saha S, Moore RD, Beach MC. Higher quality communication and relationships are associated with improved patient engagement in HIV care. J Acquir Immune Defic Syndr. 2013;63(3):362.

10. Beach MC, Keruly J, Moore RD. Is the quality of the patient-provider relationship associated with better adherence and health outcomes for patients with HIV? J Gen Intern Med. 2006;21(6):661.

11. Yonah G, Fredrick F, Leyna G. HIV serostatus disclosure among people living with HIV/AIDS in Mwanza, Tanzania. AIDS Res Ther. 2014;11(1):5.

12. Tshweneagae GT, Oss VM, Mgutshini T. Disclosure of HIV status to sexual partners by people living with HIV. curationis. 2015:38(1):1-6.

13. Rapid Response Service. Rapid Response: Disclosure of HIV-Positive Status. Toronto, ON: Ontario HIV Treatment Network; 2013. Updated November 2014
14. Sprague L, Simon S, Sprague C. Employment discrimination and HIV stigma: survey results from civil society organisations and people living with HIV in Africa. Afr J AIDS Res. 2011;10(sup1):311-24.

15. Ssali SN, Atuyambe L, Tumwine C, Segujja E, Nekesa N, Nannungi A, Ryan G, Wagner G. Reasons for disclosure of HIV status by people living with HIV/ AIDS and in HIV care in Uganda: an exploratory study. AIDS Patient Care STDs. 2010;24(10):675-81.

16. Lee SJ, Li L, lamsirithaworn S, Khumtong S. Disclosure challenges among people living with HIV in Thailand. Int J Nurs Pract. 2013;19(4):374-80.

17. Abayneh W, Obse N, Naba T. Factors Associated With Level of Adherence to Antiretroviral Therapy in People Living with HIV/AIDS at Adama Hospital Medical College Art Clinic, Oromiya Regional State, Ethiopia. International Journal of HIV/AIDS Prevention, Education and Behavioural Science. 2017; 3(3):22-27. https://doi.org/10.11648/j.ijhpebs.20170303.11.

18. Tsega B, Srikanth BA, Shewamene Z. Determinants of non-adherence to antiretroviral therapy in adult hospitalized patients, Northwest Ethiopia. Patient Prefer Adherence. 2015;9:373.

19. Federal Democratic Republic of Ethiopia. Country Progress Report on HIV/ AIDS response. 2012

20. Lakew $Y$, Benedict S, Haile D. Social determinants of HIV infection, hotspot areas and subpopulation groups in Ethiopia: evidence from the National Demographic and health survey in 2011. BMJ Open. 2015;5(11):e008669.

21. Programme UND: Responding to the HIV epidemic in Ethiopia. Available at https://www.undp.org/content/undp/en/home/librarypage/povertyreduction/supporting_transformationalchange/hiv-epidemic-ethiopia-casestudy-transformational-change.html. 2 Apr 2019.

22. Moher D, Liberati A, Tetzlaff J, et al. Preferred reporting items for systematic reviews and meta-analyses. PLoS Med. 2009;6:1-2 https://journals.plos.org/ plosmedicine/article?id=10.1371/journal.pmed.0060001.

23. Stang A. Critical evaluation of the Newcastle-Ottawa scale for the assessment of the quality of nonrandomized studies in meta-analyses. Eur J Epidemiol. 2010;25(9):603-5.

24. Huedo-Medina TB, Sánchez-Meca J, Marín-Martínez F, Botella J. Assessing heterogeneity in meta-analysis: Q statistic or $\mathrm{I}^{2}$ index? Psychol Methods. 2006;11(2):193.

25. Rendina-Gobioff G. Detecting publication bias in random effects metaanalysis: An empirical comparison of statistical methods. 2006. https:// scholarcommons.usf.edu/etd/2671.

26. Mirkena K. Assessment of Antiretroviral Therapy Adherence and Associated Factors among Adult HIV-Infected Persons in Oromia Special Zone Surrounding Finfine, 2017 (Doctoral dissertation, Addis Ababa University). Available at http://localhost:80/xmlui/handle/123456789/11872.

27. Negesa L, Demeke E, Mekonnin W. Adherence to Antiretroviral Therapy and Factors affecting among People Living with HIV/AIDS and Taking Antiretroviral Therapy, Dire Dawa Town, Eastern Ethiopia. J Infect Dis Treat. 2017;3(1):5

28. Abera A, Fenti B, Tesfaye T, Balcha F. Factors influencing adherence to antiretroviral therapy among people living with HIV/AIDS at ART Clinic in Jimma University teaching hospital, Southwest Ethiopia. J Pharma Reports. 2015;1(101):2.

29. Ejigu SH, Rike WA, Angamo MT. Medication adherence and associated factors among patients on highly active antiretroviral therapy in Nekemte hospital, Ethiopia. Gazi Med J. 2014;20(3):199-208.

30. Gebrezgabher BB, Kebede Y, Kindie M, Tetemke D, Abay M, Gelaw YA Determinants to antiretroviral treatment non-adherence among adult HIV/ AIDS patients in northern Ethiopia. AIDS Res Ther. 2017;14(1):16.

31. Firdu N, Enquselassie F, Jerene D. HIV-infected adolescents have low adherence to antiretroviral therapy: a cross-sectional study in Addis Ababa, Ethiopia. Pan Afr Med J. 2017, 27(1). Available at https://doi.org/10.11604/ pamj.2017.27.80.8544. [AJOL African Journals Online].

32. Demeke $B$, Chanie T. Adherence to antiretroviral therapy and associated factors among patients living with HIV/AIDS in Dessie referral hospital, northern Ethiopia. Int J Pharm Sci Res. 2014;5(9):572-81.

33. Alagaw A, Godana W, Taha M, Dejene T. Factors associated with antiretroviral treatment adherence among adult patients in WolaitaSoddo hospital, Wolaita zone, southern Ethiopia. Sci J Public Health. 2014;2:69-77.

34. Asmare $M$, Aychiluhem $M$, Ayana $M$, Jara D. Level of ART adherence and associated factors among HIV sero-positive adult on highly active antiretroviral therapy in Debre Markos Referral Hospital, Northwest Ethiopia. J Antivir Antiretrovir. 2014;6:120-6.

35. Gelan Z. Adherence to Antiretroviral Therapy among Adult People Living with HIV/AIDS on Highly Active Antiretroviral Therapy at Selected Health 
Centers in Wolaita and Gamo Gofa Zones, South Ethiopia, 2010 ( Master thesis, Addis Ababa University).

36. Ketema AK, Weret ZS. Assessment of adherence to highly active antiretroviral therapy and associated factors among people living with HIV at Debrebrihan referral hospital and health center, Northeast Ethiopia: a cross-sectional study. HIV/AIDS (Auckland, NZ). 2015;7:75.

37. Mitiku H, Abdosh T, Teklemariam Z. Factors affecting adherence to antiretroviral treatment in harari national regional state, eastern Ethiopia. Isrn Aids. 2013;2013.

38. Mohammed AY, Ahmed MB, Tefera TB. Assessment of factors affecting art adherence among people living with human immune virus in bale robe hospital, south East Ethiopia. Am J Public Health. 2015;3(2):60-7.

39. Smith R, Rossetto K, Peterson BL. A meta-analysis of disclosure of one's HIVpositive status, stigma and social support. AIDS Care. 2008;20(10):1266-75.

40. Maman S, Medley A. HIV status disclosure to sexual partners: rates, barriers and outcomes for women. Geneva: World Health Organization, Department of Gender and Women's Health; 2007.

41. Yu Y, Luo D, Chen X, Huang Z, Wang M, Xiao S. Medication adherence to antiretroviral therapy among newly treated people living with HIV. BMC Public Health. 2018;18(1):825.

42. Kumarasamy N, Safren SA, Raminani SR, Pickard R, James R, Krishnan AS, Solomon S, Mayer KH. Barriers and facilitators to antiretroviral medication adherence among patients with HIV in Chennai, India: a qualitative study. AIDS Patient Care \& STDs. 2005;19(8):526-37.

43. DiMatteo MR. Social support and patient adherence to medical treatment: a meta-analysis. Health Psychol. 2004;23(2):207.

44. Uthman OA, Magidson JF, Safren SA, Nachega JB. Depression and adherence to antiretroviral therapy in low-, middle-and high-income countries: a systematic review and meta-analysis. Current HIV/AIDS Reports. 2014;11(3):291-307.

45. Hardon A, Davey S, Gerrits T, Hodgkin C, Irunde H, Kgatlwane J, Kinsman J, Nakiyemba A, Laing R. Organization WH: From access to adherence: the challenges of antiretroviral treatment: studies from Botswana, Tanzania and Uganda 2006; 2006.

46. Berhanu Z. Holy water as an intervention for HIV/AIDS in Ethiopia. J HIV/ AIDS Soc Serv. 2010;9(3):240-60.

\section{Publisher's Note}

Springer Nature remains neutral with regard to jurisdictional claims in published maps and institutional affiliations.

Ready to submit your research? Choose BMC and benefit from:

- fast, convenient online submission

- thorough peer review by experienced researchers in your field

- rapid publication on acceptance

- support for research data, including large and complex data types

- gold Open Access which fosters wider collaboration and increased citations

- maximum visibility for your research: over $100 \mathrm{M}$ website views per year

At $\mathrm{BMC}$, research is always in progress.

Learn more biomedcentral.com/submissions 